\title{
Pesquisa de Salmonella em Produtos À Base de Amendoim
}

Izabel da Silva (I), Dennis Henrique da Silva (I), Eduardo Duarte (I), Neusely da Silva (I), Maristela Nascimento (I)

(I) ITAL - Instituto de Tecnologia de Alimentos (Av. Brasil 2880, Campinas/SP, Brasil, 13070178)

\section{Resumo}

Os produtos derivados de amendoim são largamente consumidos no Brasil e no mundo, contudo, apesar dos relatos de surtos de salmonelose no exterior, não há dados a respeito da contaminação do amendoim por Salmonella em produtos brasileiros. Portanto, o objetivo deste trabalho foi investigar a presença de enterobactérias, coliformes e Salmonella em produtos à base de amendoim comercializados nos Estados da Bahia, Minas Gerais e São Paulo. Foram analisadas 100 amostras de diferentes produtos (amendoim cru com casca e descascado, amendoim cozido, amendoim torrado, confeitos doces e salgados, doces diversos e pasta de amendoim), sendo 12 amostras da Bahia, 22 de Minas Gerais e 66 de São Paulo. A pesquisa de Salmonella foi realizada em 250g de amostra por método de imunoensaio, utilizando o sistema Mini-Vidas. Para a contagem de enterobactérias foi utilizado o ágar Vermelho Violeta Bile com Glicose (VRBG), enquanto para coliformes totais e Escherichia coli foi empregado Petrifilm. Além das análises microbiológicas também foram verificados o pH e a atividade de água (aw) das amostras. Os resultados de aw dos produtos variaram entre 0,21 e 0,99, já os valores de $\mathrm{pH}$ ficaram entre 5,53 a 7,50. Foi detectada Salmonella em apenas uma amostra de amendoim cru com casca proveniente do Estado da Bahia. Coliformes totais foram isolados em 6 amostras da Bahia (3,90 a 8,02 log UFC/g), em 1 de Minas Gerais (1,48 log UFC/g) e em 6 de São Paulo (1,00 a 3,20 log UFC/g), enquanto enterobactérias estavam presentes em todas as 12 amostras

\footnotetext{
Referência:

Izabel da Silva, Dennis Henrique da Silva, Eduardo Duarte, Neusely da Silva, Maristela Nascimento. Pesquisa de Salmonella em Produtos À Base de Amendoim. In: Anais do 12을 Congresso Latinoamericano de Microbiologia e Higiene de Alimentos - MICROAL 2014 [= Blucher Food Science Proceedings, num.1, vol.1]. São Paulo: Editora Blucher, 2014. 
analisadas da Bahia (1,00 a 9,00 log UFC/g), em 2 de Minas Gerais (1,95 e 2,89 log UFC/g) e em 7 de São Paulo (1,40 a 3,30 log UFC/g). Foi encontrada Escherichia coli em apenas uma amostra de pasta de amendoim fabricada em São Paulo (1,30 log UFC/g). Os achados deste estudo indicam a importância do emprego de boas práticas de fabricação para obtenção de produto final seguro ao consumidor.

Palavras-Chave: Salmonella, Enterobactérias, amendoim Agência de Fomento: 